\title{
Predation contributes to invasion resistance of benthic communities against the non-indigenous tunicate Ciona intestinalis
}

\author{
C. P. Dumont $\cdot$ C. F. Gaymer $\cdot$ M. Thiel
}

Received: 4 October 2010/Accepted: 3 May 2011/Published online: 12 May 2011

(C) The Author(s) 2011. This article is published with open access at Springerlink.com

\begin{abstract}
Marine anthropogenic structures offer novel niches for introduced species but their role in the subsequent invasion to natural habitats remains unknown. Upon arrival in new environments, invaders must overcome biotic resistance from native competitors and predators if they are to establish successfully in natural habitats. We tested the hypotheses that (1) artificial structures (e.g., suspended aquaculture installations) present a niche opportunity for invasive species by providing a refuge from native benthic predators, and (2) native predators in natural benthic habitats suppress successful colonization by invaders. A recruitment experiment showed that the ascidians Pyura chilensis (native) and Ciona intestinalis (invasive) could recruit to both suspended artificial structures and natural benthic habitats. Ciona, however, was only able to establish adult populations on artificial structures. In natural benthic habitats Ciona only recruited and grew in predator-exclusion cages, because without this protection predation prevented
\end{abstract}

C. P. Dumont - C. F. Gaymer - M. Thiel

Facultad Ciencias del Mar, Universidad Católica del Norte, and Centro de Estudios Avanzados en Zonas Áridas (CEAZA), Larrondo 1281, Coquimbo, Chile

C. P. Dumont ( $\square)$

The Swire Institute of Marine Science and School of Biological Sciences, The University of Hong Kong, Pokfulam Rd, Hong Kong, People's Republic of China e-mail: cdumont@hku.hk its establishment. In predation experiments, native invertebrate and fish predators removed all invasive ascidians (recruits and adults) in benthic habitats, which contrasted with the high adult survival of the native ascidian $P$. chilensis. The refuge from a number of benthic predators facilitates the establishment of large populations of invasive species on suspended structures. We present a conceptual model of the invasion processes that includes the anthropogenic structures as a transitional stepping-stone that facilitates invasion by enhancing and prolonging propagule supply to surrounding natural communities. Those established invaders might then overcome biotic resistance during time periods when populations of consumers or competitors are weakened by natural or anthropogenic disturbances. Our results suggest that the conservation of natural habitats with a high diversity of native predators can be an effective means to prevent the spread of invasive species growing on suspended structures.

Keywords Invasibility - Enemy release · Propagule supply · Fouling · Rocky subtidal

\section{Introduction}

The increasing abundance of anthropogenic structures deployed in the sea (e.g., harbor piers, seawalls, and suspended culture systems) offer novel niches for 
opportunistic colonizers, including non-indigenous species, which often settle and establish into the fouling communities developing on these structures (Glasby and Connell 1999; Bulleri and Airoldi 2005; Herborg et al. 2009). Although these artificial structures are now recognized as invasion hotspots (Bulleri and Chapman 2010), subsequent invasions to natural habitats are limited (Glasby et al. 2007). Assessments of invasion risks around the world also report that more introduced species are found on artificial hard substrata in estuaries and bays than on open coasts (Wasson et al. 2005; Ruiz et al. 2009). Although studies have focused on the invasion process in fouling communities on artificial structures (Stachowicz et al. 1999, 2002), the factors that provide resistance to invasion in surrounding, natural, benthic communities have yet to be identified. Among the main obstacles to settlement and establishment by non-indigenous species are biotic interactions, with predation recognized as the most likely factor limiting invasion success in a number of systems (Harvey et al. 2004; Levine et al. 2004; Parker and Hay 2005; Rilov 2009). Several studies have demonstrated the efficiency of predators in limiting the abundance or distribution of marine invaders (e.g., Byers 2002a; Hunt and Yamada 2003; Castilla et al. 2004; deRivera et al. 2005), although this predation pressure may be restricted to specific habitats or communities. However, in all presently studied cases the introduced species were able to invade the natural habitats, and it remains unclear whether native predator assemblages could prevent the establishment of invasive species.

It is widely believed that exotic species establish in new geographic locations in part because natural enemies are absent, i.e. the enemy release hypothesis (Maron and Vila 2001; Keane and Crawley 2002; Torchin et al. 2003), but native predators can also consume non-native species because these lack effective defences to new predators (Colautti et al. 2004; Wanger et al. 2011). Predation can have a dramatic effect on fouling community development when large predators (e.g. sea urchins, sea stars, crabs) but also micropredators (e.g. small gastropods) are present (Osman et al. 1992; Osman and Whitlatch 1995, 2004; Nydam and Stachowicz 2007). However, predators that are naturally abundant in benthic communities can be rare in fouling communities that colonize artificial structures (Chapman 2003;
Chapman and Blockley 2009; Dumont et al. 2011). In particular, benthic predators have limited access to suspended structures (e.g. aquaculture facilities, floating pontoons) that are not directly connected to the rocky shores. Predatory fishes are sometimes attracted to artificial structures but the studies that investigated fish predation on such structures (e.g. pilings) found no or weak impact on the fouling communities (Connell 2001; Moreau et al. 2008). Indeed, in absence of predation non-native species can outcompete native fouling species on artificial substrata (Tyrrell and Byers 2007).

In this paper we focus on the role of suspended artificial structures as novel refuges from benthic predators and potentially as a source of propagules for non-indigenous species to invade natural marine communities. Specifically, we test whether the predation resistance hypothesis (i.e., native predators preventing invasion) can explain the restricted distribution of invasive species to fouling communities on artificial structures. Introduced to Chile a century ago (Castilla et al. 2005), before 1980 the invasive ascidian (sea squirt) Ciona intestinalis had not been recorded in benthic or in fouling communities in the Coquimbo region (Viviani and DiSalvo 1980). Populations only started to proliferate on suspended artificial structures during the 1990s with the growing scallop aquaculture; at the same time the dense populations of $C$. intestinalis on suspended structures were increasingly considered as a fouling pest (Uribe and Etchepare 2002). Indeed, C. intestinalis and the native ascidian Pyura chilensis largely dominate the fouling biomass on suspended scallop cultures in northern Chile (Dumont et al. 2009). Despite these growing populations on artificial structures, $C$. intestinalis, which is primarily a benthic ascidian (rocky bottoms, seagrasses) in its native range in Northern Europe (Dybern 1965), is not found in natural benthic habitats in northern Chile. A more recent but similar introduction pattern was reported in northeastern Canada where $C$. intestinalis heavily colonized oyster cultures but was also not found on the natural substratum (rock, eelgrass) (Carver et al. 2003). In contrast, the commercially exploited native ascidian $P$. chilensis, which also is a competitively dominant species in fouling communities in northern Chile (Valdivia et al. 2005), forms dense aggregations on rocky bottoms in the low intertidal and shallow subtidal zones (Davis 1995). Using field experiments 
we evaluated whether native predators were able to eliminate non-indigenous species ( $C$. intestinalis) from natural communities and compared the relative invasibility of benthic and fouling communities under different predation pressures in two bays that differ in the abundance of artificial structures. Based on our findings, we present a conceptual model of the invasion process in marine communities that incorporates the role of anthropogenic structures.

\section{Materials and methods}

Study system

Experiments were conducted on shallow rocky shores in two bays $(\sim 50 \mathrm{~km}$ apart) differing in anthropogenic activities. La Herradura $\left(29^{\circ} 59^{\prime} \mathrm{S}, 71^{\circ} 22^{\prime} \mathrm{W}\right)$ is a sheltered bay of $3.3 \mathrm{~km}^{2}$ with an important overseas port which includes several harbor walls and pilings connected to natural substrata (rocks and sand), and few aquaculture concessions $\left(0.11 \mathrm{~km}^{2}\right)$. Tongoy bay $\left(30^{\circ} 15^{\prime} \mathrm{S}, 71^{\circ} 35^{\prime} \mathrm{W}\right)$ is the most important aquaculture area $\left(23 \mathrm{~km}^{2}\right.$ of suspended scallop cultures) in northern Chile, which involves $600 \mathrm{~km}$ of long-lines, 300,000 buoys, 1 million pearl nets and lanterns and 2 million spat collector bags suspended in the water column at a depth of $<10 \mathrm{~m}$. The main portion of the bottom in both bays is sand and mud with an average depth range of 20-30 m. The general oceanographic regime is similar in both bays, which are influenced by a nearby upwelling system (see Thiel et al. 2007).

We conducted a qualitative survey (presence/ absence) of adult Ciona intestinalis and Pyura chilensis on 18 moored aquaculture buoys in Tongoy Bay. Experiments were conducted on rocky bottoms, which are dominated by small boulders that are mainly covered by coralline algae but also the resident algae Dictyota kunthii and Colpomenia sinuosa, Asparagopsis sp. and Halopteris sp.; the abundances of both $C$. intestinalis and $P$. chilensis were quantified using 20 quadrats $(50 \times 50 \mathrm{~cm})$ that were randomly placed at 3-4 m depth in Tongoy and La Herradura Bays. The most common predators were also counted in these quadrats; each quadrat was left on the bottom for 3-5 min before counting the individuals, which allowed highly mobile species (e.g., shrimps, blennid fishes) to re-emerge from shelters and crevices and reoccupy the sampled area.
The herbivorous gastropods Tegula atra, Fissurella spp., and Acanthopleura echinata were common but not included in the survey. This method permitted to estimate the densities of all predators consuming ascidians during our experiments, but remained a conservative estimate of predation pressure since it did not cover other highly mobile predators (e.g., transient fishes), and small recruits hidden in crevices. However, transient fishes were in low abundance at our sites where spearfishing is a common practice, leading to a reduction of large fish predators (see e.g. Godoy et al. 2010). Predators on sampled buoys could not be estimated because mobile species escaped while manipulating the buoys. An underwater qualitative survey, however, revealed a very low abundance of potential predators which were mostly small invertebrate recruits (e.g. crabs).

Biotic resistance

We quantified the survival rate of the invasive $C$. intestinalis and the native $P$. chilensis in two different habitats, (1) suspended structures where both species were abundant and benthic predators were absent, and (2) rocky bottoms where only the native ascidian occurred and benthic predators were abundant. Two separate survival experiments were carried out with newly recruited and adult ascidians. Recruits were obtained from settlement collectors (closed suspended mesh bags with rocks inside) deployed for 6 weeks (March-April 2007) among aquaculture structures in Tongoy Bay. The mesh bags were brought back to the Universidad Católica del Norte's laboratory in La Herradura Bay and then cut into small squares $(\sim 2 \times 2 \mathrm{~cm})$ that contained two recruits of $C$. intestinalis (average length, $13.5 \mathrm{~mm}$, $\mathrm{SD}=2.9)$ and two recruits of $P$. chilensis $(6.9 \mathrm{~mm}$, $\mathrm{SD}=1.7)$. Each piece of mesh was then tethered to a PVC panel $(15 \times 15 \mathrm{~cm})$ and either suspended at $1 \mathrm{~m}$ depth in the water column or fixed to the rocky bottom at 3-4 m depth (5 panels at each depth). The number of individuals eaten was quantified by two SCUBA divers every $15 \mathrm{~min}$ during the first hour and then after $2 \mathrm{~h}$. The experiment was repeated 4 times (on different days) in La Herradura Bay.

The ascidians for the adult survival experiment were taken from suspended structures (i.e., ropes, buoys) just prior to the experiment. One adult C. intestinalis $(70.7 \mathrm{~mm}$ in length, $\mathrm{SD}=15.7)$ and 
one adult $P$. chilensis $(29.4 \mathrm{~mm}$ in length, $\mathrm{SD}=14.7)$ were attached with a clip to opposite corners of each of 16 PVC panels $(15 \times 15 \mathrm{~cm})$. The clip held the ascidians with their basal tunic attached to the panel, and all ascidians started filtering $<5 \mathrm{~min}$ after the clipping procedure. Eight panels were suspended at $1 \mathrm{~m}$ depth in the water column and the other 8 were fixed to the rocky bottom at 3-4 m depth. In addition to the quantification of ascidians eaten, two divers identified the predator species attacking each individual ascidian during the first hour (such observation was not possible with recruits given the difficulty to identify the ascidian species that was attacked). An attack usually caused interruption of the filter feeding activity by ascidians but did not necessarily imply tunic damage or death. This experiment was repeated 3 times during daylight hours $(1,400-1,700)$ in May 2007 in La Herradura and Tongoy Bays.

Invasibility

A predator exclusion experiment was deployed on suspended artificial structures (i.e., suspended fouling community) and natural rocky bottoms (i.e., benthic community) at three sites (200-500 m apart) in each of the two bays. We used sanded PVC panels $(15 \times 15 \mathrm{~cm})$ as settlement substrata and made predator-exclusion cages $(20 \times 20 \times 5 \mathrm{~cm})$ with 5 -mm plastic mesh. This mesh size ensured passage of all recruits and minimal hydrodynamic restrictions while excluding main predators (closed cage). Open cages $(10 \times 5 \mathrm{~cm}$ apertures on each side) were used to test for cage artifacts while panels without cages were exposed to predators (3 replicate panels per each treatment per site). Recruitment panels both in benthic habitats and in the water column were attached in horizontal position, because in a previous study, we observed that recruits of the ascidians $C$. intestinalis and $P$. chilensis were more abundant on the underside of artificial structures (e.g., bottom of scallop culture cages) (Dumont et al. 2009). Ascidian larvae preferentially settle on shaded substratum (Miller and Etter 2008), which had also been confirmed for $C$. intestinalis (Rius et al. 2010). Panels on rocky bottoms were attached with rigid wire cables (at $5 \mathrm{~cm}$ from the bottom) to mesh bags $(92 \times 59 \mathrm{~cm})$ filled with rocks (moorings) at $4-5 \mathrm{~m}$ depth. The suspended structure treatment consisted of panels attached to a wire ring, which was suspended $1 \mathrm{~m}$ below the surface on a moored surface buoy in proximity to piers ( $\sim 20 \mathrm{~m}$ from rocky shore) in $\mathrm{La}$ Herradura bay and to aquaculture facilities $(\sim 200 \mathrm{~m}$ offshore) in Tongoy bay. At 2-week intervals we visited the sites in the two bays to scrub the exterior of the cages cleaning off encrusting organisms; we also removed recruits of rock shrimp, crabs and small blennid fishes from the cages on the bottom (these predators were never found in suspended cages). After 3 months (from October to December 2007), we counted the number of recruits of both $C$. intestinalis and $P$. chilensis on the underside of panels. The observations from the $1-\mathrm{cm}$ edge of the panels were excluded to eliminate potential edge effects (Sousa 1984; terHorst and Dudgeon 2009).

\section{Data analyses}

To determine if survival on the rocky bottom after 120 min differed between the two ascidian species we used stratified $2 \times 2$ contingency tables (stratified variable day) and the Mantel-Haenszel test; data for juveniles and adults were analyzed separately. To examine whether predators preferentially attacked one of the two ascidian species, observations of predation attacks on adult ascidians were analyzed with $2 \times 2$ contingency tables with the day as the stratified variable for each site (3 levels). To analyze the data of the predation exclusion experiment, fourway nested ANOVAs were applied, incorporating the fixed factors bay (2 levels), predation (3 levels), habitat ( 2 levels) and the random factor site (nested within bay, 3 levels) on the response variables, abundance of $C$. intestinalis and $P$. chilensis. Heteroscedasticity in the recruitment data (caused by many zero values and the difference in variance between the 2 habitats) prevented us to apply conventional ANOVAs. We performed permutational ANOVAs, using the statistical package PERMANOVA+ to estimate with permutations the pseudo- $F$ statistic, which is an analogue of the univariate Fisher's $F$ ratio (Anderson 2001; Anderson et al. 2008). Because many zero values in the data set referred to the absence of individuals of a particular species on the recruitment panels, the matrix data were adjusted using the zero-adjusted Bray-Curtis coefficient (Clarke et al. 2006). The nested random factor site was post hoc pooled to increase the number of 
permutations when no significant difference between sites was found $(P>0.25)$ in the full model (Underwood 1997; Anderson 2001). When appropriate, a posteriori pair-wise comparisons were made using permutations and Monte Carlo sampling. Further, to examine whether competition for space could play a role in the recruitment of the two ascidians in absence of predators, we used Spearman rank correlations to evaluate the association between the abundances of $C$. intestinalis and P. chilensis.

\section{Results}

Biotic resistance

The invasive ascidian $C$. intestinalis was only found in fouling communities $(55.6 \%$ of the aquaculture buoys in Tongoy Bay) colonizing artificial structures (e.g., aquaculture installations) whereas the native ascidian, $P$. chilensis, was found in both the fouling (88.9\% of the buoys) and rocky subtidal communities (40 and $35 \%$ of sampled quadrats in La Herradura and Tongoy Bays, respectively). The adult densities of $P$. chilensis on rocky bottoms were similar in La Herradura and Tongoy Bays $(5.6 \pm 2.1$, mean $\pm \mathrm{SE}$, and $7.8 \pm 3.4$ ind. $\mathrm{m}^{-2}$, respectively, $t$ test, $t_{38}=1.69$, $P=0.58)$.

Predators rapidly consumed small ascidian recruits on rocky bottoms while no mortality was observed on panels suspended in the water column (Fig. 1a). Although survival decreased more abruptly for the invasive ascidian (40\% after $15 \mathrm{~min}$ ), recruits of both $C$. intestinalis and $P$. chilensis experienced a similarly low survival $(<15 \%)$ after $2 \mathrm{~h}$ on rocky bottoms (Mantel-Haenszel test: $\chi^{2}=0.64, P=0.42$, $n=72$ ). A low survival rate of adults was also observed for $C$. intestinalis $(<30 \%$ after $2 \mathrm{~h})$ on rocky bottoms in La Herradura $\left(\chi^{2}=22.46\right.$, $P<0.001, n=48)$ and Tongoy Bays $\left(\chi^{2}=22.46\right.$, $P<0.001, \quad n=48)$, while $100 \%$ of the adult P. chilensis survived (Fig. 1c-d). As for small recruits, no predation on adults of either ascidian occurred on panels suspended in the water column.

Eight different generalist predator species, 4 crustaceans, 2 echinoderms and 2 blennid fishes, were observed attacking (but not necessarily consuming) adults of the two ascidian species (Table 1). All these predators preyed successfully (i.e., prey was partially or fully eaten) on adults of the invasive $C$. intestinalis but not the native ascidian. The most abundant predator was the rock shrimp Rhyncocinetes
Fig. 1 Survival (means \pm SE) over time of a recruit and $\mathbf{c}$, $\mathbf{d}$ adult ascidians Ciona intestinalis (invasive) and Pyura chilensis (native) on panels suspended in the water column and the rocky bottom in La Herradura and Tongoy Bays. b The most common predator, the rock shrimp Rhyncocinetes typus, consuming an adult C. intestinalis attached to the rocky bottom

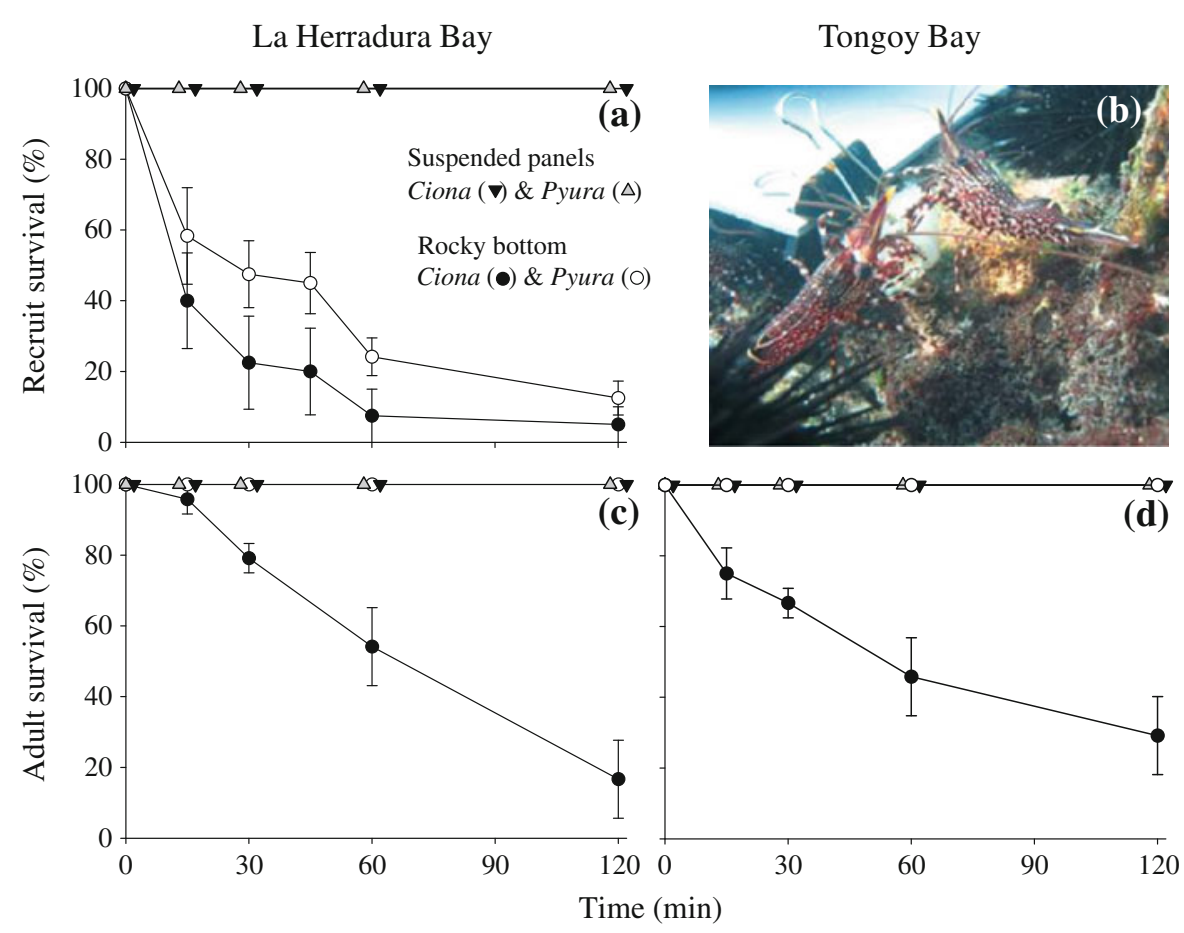


Table 1 Percentage of adult ascidians (invasive Ciona intestinalis and native Pyura chilensis) attacked by predators on the rocky bottom in La Herradura and Tongoy Bays

\begin{tabular}{|c|c|c|c|c|c|c|}
\hline \multirow[t]{2}{*}{ Predator } & \multicolumn{3}{|c|}{ La Herradura Bay } & \multicolumn{3}{|l|}{ Tongoy Bay } \\
\hline & $\begin{array}{l}\text { Ciona } \\
\text { attacked (\%) }\end{array}$ & $\begin{array}{l}\text { Pyura } \\
\text { attacked (\%) }\end{array}$ & $\begin{array}{l}\text { Predator density } \\
\text { (ind. } \mathrm{m}^{-2} \text { ) }\end{array}$ & $\begin{array}{l}\text { Ciona } \\
\text { attacked (\%) }\end{array}$ & $\begin{array}{l}\text { Pyura } \\
\text { attacked (\%) }\end{array}$ & $\begin{array}{l}\text { Predator density } \\
\text { (ind. } \mathrm{m}^{-2} \text { ) }\end{array}$ \\
\hline$R$. typus & 87.5 & 70.8 & $93.6(11.6)$ & $62.5^{*}$ & 8.3 & $25.4(5.6)$ \\
\hline P. edwardsii & 4.2 & 0.0 & $6.8(2.8)$ & 0.0 & 0.0 & $40.8(18.3)$ \\
\hline P. barbiger & 4.2 & 0.0 & $1.0(0.4)$ & 25.0 & 8.3 & $2.6(0.5)$ \\
\hline C. setosus & 0.0 & 0.0 & $0.0(0.0)$ & 4.2 & 0.0 & $0.0(0.0)$ \\
\hline T. niger & 4.2 & 0.0 & $6.2(1.7)$ & 0.0 & 0.0 & $2.4(1.1)$ \\
\hline H. helianthus & 0.0 & 0.0 & $0.0(0.0)$ & 4.2 & 0.0 & $0.0(0.0)$ \\
\hline S. viridis & $70.8 *$ & 29.8 & $2.0(0.5)$ & $70.8 *$ & 33.3 & $10.2(1.6)$ \\
\hline H. sordidus & 12.5 & 4.2 & $1.4(0.5)$ & 25.0 & 8.3 & $5.4(1.1)$ \\
\hline
\end{tabular}

The predators (mean density \pm SE) were crustaceans (Rhyncocinetes typus, Pagurus edwardsii, Paraxanthus barbiger, Cancer setosus), echinoderms (Tetrapygus niger, Heliaster helianthus), and blennid fishes (Scartichthys viridis, Hypsoblennius sordidus). An attack usually caused interruption of the filter feeding activity but did not necessarily imply tunic damage or death. The same ascidian individual could be attacked by several predator species. * Indicates that the predator preferentially attacked the given ascidian (Mantel-Haenszel test, $P<0.05$ )

typus, which most frequently attacked and consumed the ascidians (Fig. 1b). In Tongoy Bay, the shrimp selectively attacked the invasive $C$. intestinalis (Mantel-Haenszel test: $\chi^{2}=12.49, P<0.001, n=$ 48). In contrast, in La Herradura Bay, where the shrimp were much more abundant, they attacked both adult ascidian species $\left(\chi^{2}=1.25, P=0.26, n=48\right)$ but only $C$. intestinalis was consumed. Shrimp (groups of 3-5 individuals) were usually the first predators to attack (typically within $5 \mathrm{~min}$ ) and consume the nonnative prey organisms. However, the aggressive omnivorous blennid fish Scartichthys viridis rapidly followed, causing the shrimp to withdraw temporarily. The blennid fish was the most efficient and fastest predator on $C$. intestinalis, selectively attacking $C$. intestinalis in both La Herradura (Mantel-Haenszel test: $\left.\chi^{2}=6.40, P=0.01, n=48\right)$ and Tongoy Bay $\left(\chi^{2}=5.55, P=0.02, n=48\right)$, completely consuming an adult in 3-4 bites. It was difficult to discern which predator killed the ascidian since $45.8 \%$ of the ascidians were attacked by both the rock shrimp and the blennid fish. Attacks on adult $P$. chilensis appeared to be mostly directed towards epibionts on the tunic and never were lethal for the ascidian.

Invasibility

After 3 months, all recruitment panels suspended in the water column in Tongoy Bay (which supported a large invader population on suspended aquaculture structures) were colonized by large numbers of C. intestinalis (mean abundance ranging from 131 to 169 ind. per $100-\mathrm{cm}^{2}$ panel area) regardless of predator exclusion treatments (Table 2; Fig. 2). In contrast, in the natural benthic habitat $C$. intestinalis was not able to recruit where predators were allowed access in open cages or uncaged surfaces. However, when benthic predators were excluded, $C$. intestinalis also recruited on rocky bottoms, at a density of $26.8 \pm 8.4$ ind. per $100-\mathrm{cm}^{2}$ panel area (Fig. 2). In closed cages in Tongoy Bay, recruitment of C. intestinalis was 6 times greater on suspended panels than on rocky bottoms (Table 2). A similar pattern was found in La Herradura Bay (where only a small invader population is present), but with a much lower recruitment density $\left(0.1-1.3\right.$ ind. per $100-\mathrm{cm}^{2}$ panel area) and there was no recruitment on suspended panels that were not protected by cages (Fig. 2). The native $P$. chilensis also did not recruit onto suspended panels without cages but recruited into closed and open cages; open cages might have excluded transient fish grazers (which were occasionally observed in La Herradura Bay) in similar ways as closed cages. Recruitment of $P$. chilensis was very low on suspended panels in Tongoy Bay but occurred in all treatments (Table 2; Fig. 2). The absence of $P$. chilensis on uncaged panels or in open cages on rocky bottoms suggested there was intense 
Table 2 Statistical summary of permutational ANOVAs to test for the effects of habitat (suspended artificial structures and natural rocky bottom) and predator access (open cage, no cage, closed cage) on the abundances of the invasive Ciona intestinalis and native Pyura chilensis ascidians at two bays (Tongoy and La Herradura) which differ in propagule supply

\begin{tabular}{lrrrrl}
\hline Source & $d f$ & \multicolumn{1}{l}{ SS } & \multicolumn{1}{l}{ MS } & Pseudo- $F$ & $P$ \\
\hline Ciona intestinalis & & & & \\
Bay & 1 & $64,061.0$ & $64,061.0$ & 405.2 & $<0.001$ \\
Habitat & 1 & $40,356.0$ & $40,356.0$ & 255.3 & $<0.001$ \\
Predation & 2 & $11,106.0$ & $5,553.2$ & 35.1 & $<0.001$ \\
Ba $\times$ Ha & 1 & $26,611.0$ & $26,611.0$ & 168.3 & $<0.001$ \\
Ba $\times$ Pr & 2 & $4,384.8$ & $2,192.4$ & 13.9 & $<0.001$ \\
Ha $\times \operatorname{Pr}$ & 2 & $4,881.7$ & $2,440.8$ & 15.4 & $<0.001$ \\
Ba $\times$ Ha $\times$ Pr & 2 & $9,998.8$ & $4,999.4$ & 31.6 & $<0.001$ \\
Pooled & 96 & $15,176.0$ & 158.1 & & \\
Pyura chilensis & & & & & \\
Bay & 1 & $7,761.8$ & $7,761.8$ & 41.9 & $<0.001$ \\
Habitat & 1 & $7,780.0$ & $7,780.0$ & 42.0 & $<0.001$ \\
Predation & 2 & $6,448.0$ & $3,224.0$ & 17.4 & $<0.001$ \\
Ba $\times$ Ha & 1 & $4,166.4$ & $4,166.4$ & 22.5 & $<0.001$ \\
Ba $\times \operatorname{Pr}$ & 2 & $6,513.5$ & $3,256.7$ & 17.6 & $<0.001$ \\
Ha $\times$ Pr & 2 & $2,761.1$ & $1,380.6$ & 7.5 & $<0.001$ \\
Ba $\times$ Ha $\times$ Pr & 2 & $3,445.5$ & $1,722.8$ & 9.3 & $<0.001$ \\
Pooled & 96 & $17,763.0$ & 185.0 & & \\
\hline The & & & & \\
\hline
\end{tabular}

The nested factor site ( 3 levels) and its interactions with the others factors were pooled when no difference between sites was found $(P>0.25)$ in the full model. $P$ values were estimated with 10,000 permutations

predation on recruits on open surfaces (Fig. 2). In the absence of predators (closed cage treatment), the abundances of $P$. chilensis and $C$. intestinalis were negatively correlated on both suspended structures (Spearman's $r=-0.82, n=18, P<0.001$ ) and rocky bottoms $(r=-0.83, n=11, P<0.001)$, which suggests intra-guild interference at an early stage of colonization on recruitment plates.

\section{Discussion}

Anthropogenic structures in marine systems provide a spatial refuge from predation permitting the establishment of introduced species (Glasby and Connell 1999; Bulleri and Chapman 2010), and thereby enhancing the risk of their subsequent invasion into natural habitats. Our findings in Chile illustrate how suspended structures may facilitate the supply of propagules of introduced species (Bulleri and Airoldi 2005; Herborg et al. 2009), and how native predators can suppress the spread of invasive species into natural benthic communities. The invasive ascidian, Ciona intestinalis, despite the well-established populations on artificial structures, appears unable to colonize surrounding, natural communities due to predation pressure from native benthic species.

The successful establishment of $C$. intestinalis in suspended fouling communities but not in benthic communities reveals that post-settlement processes strongly influence its ability to invade natural habitats. While predation pressure on ascidians was very low on suspended structures, both recruits and adults of $C$. intestinalis suffered from intense predation on natural rocky bottoms. In contrast, the native Pyura chilensis is able to establish in natural rocky habitats, probably as a result of achieving a size refuge from predation once recruits outgrow safe microhabitats (e.g., crevices, kelp holdfasts, among conspecifics). Despite being consumed by a wide range of predators when young (Cea 1973), the thick cellulose tunic developed by adult $P$. chilensis offers efficient protection against many benthic predators, whereas adult $C$. intestinalis with their fragile tunic remain vulnerable to most benthic predators. In its native range, $C$. intestinalis can occur in large aggregations on rocky bottoms (Dybern 1965), and few predator species, apart from the sea star Asterias rubens (Gulliksen and Skjaevel 1973), have been observed feeding on it (I. Svane, J. Petersen, J. Havenhand, personal observation). In its introduced range in Chile, we observed a high diversity and abundance of predators (e.g., crabs, shrimps and blennid fishes) feeding on $C$. intestinalis on rocky bottoms during our surveys and predation experiments. Recruits of these predators were removed on several instances from cages on rocky bottoms but were never found on suspended structures. Interestingly, Carver et al. (2003) observed a sudden increase of the introduced C. intestinalis on suspended oyster cultures in northeastern Canada, but did not find any $C$. intestinalis on natural substrata (rocks, eelgrass). They suggested that this lack of $C$. intenstinalis in benthic habitats is due to its vulnerability to several native benthic predators (sea stars, crabs).

Biotic resistance to invasion, therefore, differed at the community-level (suspended vs. benthic 


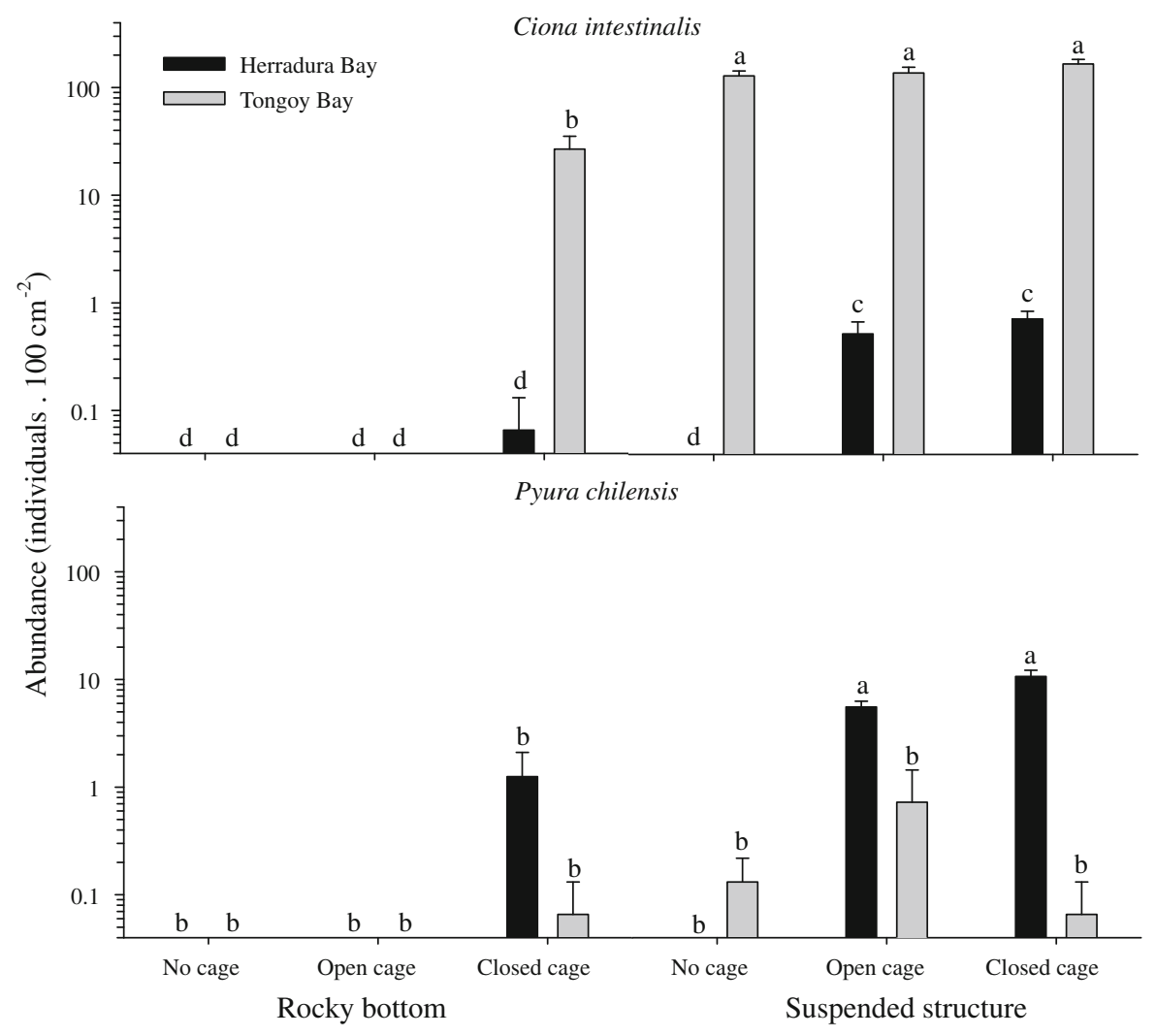

Fig. 2 Recruit abundance (means \pm SE) of the invasive Ciona intestinalis and native Pyura chilensis ascidians on suspended structures (i.e. water column) and the rocky bottom in presence (open cage, no cage) or absence (closed cage) of predators at two bays. Predators prevented recruitment of

communities) as well as during ontogeny (recruits vs. adults), yet adult survival is critical to population growth and therefore invasion success (Dudas et al. 2007). C. intestinalis can reach sexual maturity and reproduce within 2-4 months (Dybern 1965; Carver et al. 2003), allowing this species to reproduce successfully before aquaculture structures are retrieved from the sea and cleaned, which occurs about every 4 months (von Brand et al. 2006). While C. intestinalis rapidly colonized new substrata and quickly covered all suspended substrata during our 3-month experiment (see also Uribe and Etchepare 2002), colonization and initial growth of the native ascidian $P$. chilensis is much slower and it only starts to dominate suspended structures after 4-6 months, and eventually outcompetes the short-lived $C$. intestinalis (Valdivia et al. 2005; Cifuentes et al. 2010). In the absence of predators (exclusion treatments) in ascidians on rocky bottoms but not on suspended structures (see Table 2 for permutational ANOVA results). Means with the same letter were not significantly different $(P<0.01)$ based on the PERMANOVA pair-wise tests within species

both suspended and benthic communities, the invasive ascidian $C$. intestinalis was more successful in early-stage colonization of new substrata than the native $P$. chilensis in Tongoy Bay. Interspecific competition, therefore, appears to play an important role in the establishment of $C$. intestinalis in fouling communities (Stachowicz et al. 1999; Blum et al. 2007; Ramsay et al. 2008) but this interaction seems unimportant in benthic communities exposed to natural predation pressure. Our findings demonstrate the importance of a high diversity and abundance of predators within a community in preventing the establishment of non-indigenous species. As a result, the disruption of predation pressure due to disturbances in natural communities may weaken this interaction and provide invasion opportunities for latent populations of non-indigenous species growing on artificial structures. 
Based on the above considerations we propose a conceptual model that postulates a fundamental difference in invasibility potential between suspended and benthic communities due to differences of in situ predation pressure (Fig. 3). Invasibility is mediated in terms of variation in the timing and intensity of propagule supply. Human-mediated propagule introductions are usually singular events (e.g., ballast water) that can sometimes occur repeatedly (Carlton and Geller 1993; Verling et al. 2005) but this sporadic propagule supply is often too small to permit introduced species to invade natural habitats due to the strong predation pressure in natural communities (Drake and Lodge 2006), i.e., the Risky Roulette scenario (Fig. 3). In contrast, species that are introduced during these singular events may be more successful in establishing on anthropogenic structures (e.g., aquaculture installations), which offer an alternative step in the invasion process due to space availability and low predation pressure. Initial establishment in fouling communities might allow introduced species to adapt to their new environment, and to continuously produce large numbers of propagules, thereby generating conditions for the subsequent successful invasion of surrounding benthic communities (Lee and Bruno 2009), i.e., the Persistent Pressure scenario (Fig. 3). Our study matches this scenario: the exclusion of predators resulted in the successful recruitment of $C$. intestinalis on rocky bottoms via propagules that were likely supplied from established populations on aquaculture installations. In another study, also in northern Chile, the exclusion of benthic predators on pilings that were connected to rocky bottom (i.e., accessible to sea urchin and rock shrimp predators) resulted in an abrupt colonization by the invasive bryozoan Bugula neritina (Dumont et al. 2011). While benthic predators can suppress the recruitment of $B$. neritina, large bryozoan populations (source of propagule supply) occurred on pilings isolated on sandy bottoms, where predators from the rocky shore have no or only limited access (Dumont et al. 2011).

Empirical and theoretical studies suggest that a large and constant release of propagules (i.e., Persistent Pressure Scenario) into a location can enable an invading population to overcome biotic resistance (Levine 2000; Lockwood et al. 2005; Von Holle and Simberloff 2005; Hollebone and Hay 2007; Chadwell and Engelhardt 2008) but to date, despite the huge source population of the invader $C$. intestinalis on aquaculture installations, no successful invasion of natural benthic communities has occurred. This resistance to invasion is probably a result of strong and diverse predation pressure and also competition from mature native communities. A common consensus is that disturbed communities are more easily invaded, with propagule supply determining invasibility (Buckley et al. 2007; Altman and Whitlatch

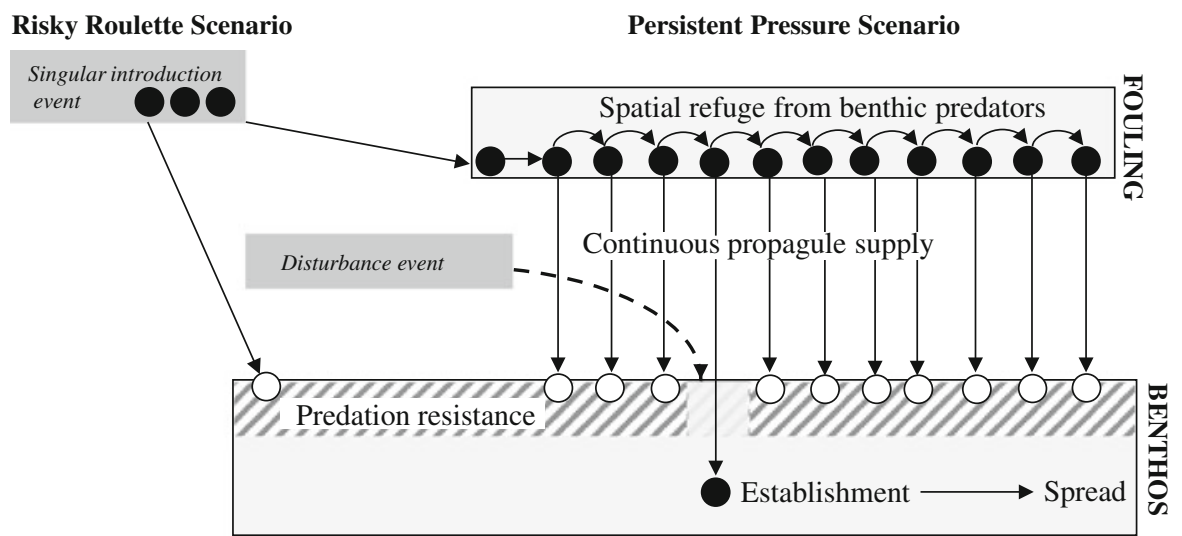

Fig. 3 A hypothesized conceptual model of potential invasion processes in marine benthic communities. The model shows two scenarios: Risky Roulette and Persistent Pressure, incorporating the importance of propagule supply and predation resistance. Non-native populations (black dots) successfully establish on anthropogenic structures that are inaccessible to most benthic predators. Despite large propagule supply and successful settlement, colonization (white dots) of natural habitats fails due to resistance imposed by benthic predators. Disturbance events (natural or anthropogenic) may cause a temporal reduction or absence of predation pressure, allowing invaders to overcome predation resistance and establish in natural habitats 
2007; Clark and Johnston 2009). Our model integrates the selection regime modification (Byers 2002b) suggesting that disturbance events (e.g., overfishing, pollution or periodic variation in climate conditions such as El Niño Southern Oscillation, ENSO), which may reduce natural predation and competition pressure, could rapidly result in the establishment of $C$. intestinalis in benthic communities. Possibly, the appearance and massive spread of the green alga Codium fragile in benthic habitats of northern Chile after the 1997-1998 El Niño event (Neill et al. 2006) is an example of a successful Persistent Pressure scenario: $C$. fragile first established and spread on artificial structures (including suspended aquaculture installations), and likely entered the ecosystem via these structures. C. fragile subsequently invaded benthic habitats during/after the El Niño disturbance that opened space previously occupied by natural kelp populations (Vega et al. 2005). This process could also be facilitated in some areas by small-scale disturbances due to kelp extraction for abalone hatcheries.

The Persistent Pressure scenario proposed in this study can help explain the invasion process of several invasive species that are susceptible to benthic predators (e.g., the ascidian Ciona intestinalis, the bryozoan Bugula neritina, and the green alga Codium fragile), but caution should be used in extrapolating the role of benthic predators in suppressing recruitment of invasive species. This may be of particular importance in marine systems that still have a high diversity of predators (i.e., that have not yet been severely impacted by human activities) and where mechanisms of biotic resistance may only be compromised during unpredictable natural disturbance events. Considering propagule pressure as a primary controller of invasions (Drake and Lodge 2006; Simberloff 2009), our results suggest that within a management context, limiting the supply of propagules from artificial structures could be an effective strategy for reducing the risk of invasion into natural benthic communities (Dumont et al. 2009). The most effective and desirable means to prevent species invasions, however, is the conservation of natural benthic communities with a high diversity of native predators (see also Hulme 2006).

Acknowledgments We are grateful to J.D. Urriago, J.C. Astudillo, M. Bravo, F. Schneider and M. Thompson for their help with the experiments. Special thanks to L.G. Harris who provided useful ideas at the early stage of the study. We thank B. Broitman, J.H. Himmelman, S.A. Navarette, G. Ruiz, S. Sampson, G. Williams, B. Worm, and three anonymous reviewers and the editor J. Byers for comments on the manuscript. Financial support for this study was provided by FONDECYT 3070048 to CPD.

Open Access This article is distributed under the terms of the Creative Commons Attribution Noncommercial License which permits any noncommercial use, distribution, and reproduction in any medium, provided the original author(s) and source are credited.

\section{References}

Altman S, Whitlatch RB (2007) Effects of small-scale disturbance on invasion success in marine communities. J Exp Mar Biol Ecol 342:15-29

Anderson MJ (2001) Permutation tests for univariate or multivariate analysis of variance and regression. Can J Fish Aquat Sci 58:626-639

Anderson MJ, Gorley RN, Clarke KR (2008) PERMANOVA+ for PRIMER: guide to software and statistical methods. PRIMER-E, Plymouth

Blum JC, Chang AL, Liljesthrom M, Schenk ME, Steinberg MK, Ruiz GM (2007) The non-native solitary ascidian Ciona intestinalis (L.) depresses species richness. J Exp Mar Biol Ecol 342:5-14

Buckley YM, Bolker BM, Rees M (2007) Disturbance, invasion and re-invasion: managing the weed-shaped hole in disturbed ecosystems. Ecol Lett 10:809-817

Bulleri F, Airoldi L (2005) Artificial marine structures facilitate the spread of a non-indigenous green alga, Codium fragile ssp. tomentosoides, in the north Adriatic Sea. J Appl Ecol 42:1063-1072

Bulleri F, Chapman MG (2010) The introduction of coastal infrastructure as a driver of change in marine environments. J Appl Ecol 47:26-35

Byers JE (2002a) Physical habitat attribute mediates biotic resistance to non-indigenous species invasion. Oecologia 130:146-156

Byers JE (2002b) Impact of non-indigenous species on natives enhanced by anthropogenic alteration of selection regimes. Oikos 97:449-458

Carlton J, Geller J (1993) Ecological roulette: the global transport of nonindigenous marine organisms. Science 261:78-82

Carver CE, Chisholm A, Mallet AL (2003) Strategies to mitigate the impact of Ciona intestinalis (L.) biofouling on shellfish production. J Shellfish Res 22:621-631

Castilla J, Guiñez R, Caro A, Ortiz V (2004) Invasion of a rocky intertidal shore by the tunicate Pyura praeputialis in the Bay of Antofagasta, Chile. Proc Natl Acad Sci USA 101:8517

Castilla JC, Uribe M, Bahamonde N, Clarke M, DesqueyrouxFaundez R, Kong I, Moyano H, Rozbaczylo N, Santelices B, Valdovinos C, Zavala P (2005) Down under the 
southeastern Pacific: marine non-indigenous species in Chile. Biol Invasions 7:213-232

Cea G (1973) Biología del Piure (Pyura chilensis Molina, 1782; Chordata, Tunicata, Ascidiacea). Gayana Zool 28:1-65

Chadwell T, Engelhardt K (2008) Effects of pre-existing submersed vegetation and propagule pressure on the invasion success of Hydrilla verticillata. J Appl Ecol 45:515-523

Chapman MG (2003) Paucity of mobile species on constructed seawalls: effects of urbanization on biodiversity. Mar Ecol Prog Ser 264:21-29

Chapman MG, Blockley DJ (2009) Engineering novel habitats on urban infrastructure to increase intertidal biodiversity. Oecologia 161:625-635

Cifuentes M, Krueger I, Dumont CP, Lenz M, Thiel M (2010) Does primary colonization or community structure determine the succession of fouling communities? J Exp Mar Biol Ecol 395:10-20

Clark GF, Johnston EL (2009) Propagule pressure and disturbance interact to overcome biotic resistance of marine invertebrate communities. Oikos 118:1679-1686

Clarke KR, Somerfield PJ, Chapman MG (2006) On resemblance measures for ecological studies, including taxonomic dissimilarities and a zero-adjusted Bray-Curtis coefficient for denuded assemblages. J Exp Mar Biol Ecol 330:55-80

Colautti RI, Ricciardi A, Grigorovich IA, MacIsaac HJ (2004) Is invasion success explained by the enemy release hypothesis? Ecol Lett 7:721-733

Connell SD (2001) Predatory fish do not always affect the early development of epibiotic assemblages. J Exp Mar Biol Ecol 260:1-12

Davis AR (1995) Over-exploitation of Pyura chilensis (Ascidiacea) in Southern Chile- the urgent need to establish marine reserves. Rev Chil Hist Nat 68:107-116

deRivera CE, Ruiz GM, Hines AH, Jivoff P (2005) Biotic resistance to invasion: native predator limits abundance and distribution of an introduced crab. Ecology 86:3364-3376

Drake J, Lodge D (2006) Allee effects, propagule pressure and the probability of establishment: risk analysis for biological invasions. Biol Invasions 8:365-375

Dudas SE, Dower JF, Anholti BR (2007) Invasion dynamics of the varnish clam (Nuttallia obscurata): a matrix demographic modeling approach. Ecology 88:2084-2093

Dumont CP, Urriago JD, Abarca A, Gaymer CF, Thiel M (2009) The native rock shrimp Rhynchocinetes typus as a biological control of fouling in suspended scallop cultures. Aquaculture 292:74-79

Dumont CP, Harris LG, Gaymer CF (2011) Anthropogenic structures as a spatial refuge from predation for the invasive bryozoan Bugula neritina. Mar Ecol Prog Ser 427:95-103

Dybern BI (1965) The life cycle of Ciona intestinalis (L.) $f$. typica in relation to the environmental temperature. Oikos 16:109-131

Glasby TM, Connell SD (1999) Urban structures as marine habitats. Ambio 28:595-598

Glasby TM, Connell SD, Holloway MG, Hewitt CL (2007) Nonindigenous biota on artificial structures: could habitat creation facilitate biological invasions? Mar Biol 151: 887-895

Godoy N, Gelcich S, Vasquez J, Castilla J (2010) Spearfishing to depletion: evidence from temperate reef fishes in Chile. Ecol Appl 20:1504-1511

Gulliksen B, Skjaevel S (1973) Sea star, Asterias rubens (L.), as predator on ascidian, Ciona intestinalis (L.), in Borgenfjorden, North Trondelag, Norway. Sarsia 52:15-20

Harvey BC, White JL, Nakamoto RJ (2004) An emergent multiple predator effect may enhance biotic resistance in a stream fish assemblage. Ecology 85:127-133

Herborg L, O'Hara P, Therriault T (2009) Forecasting the potential distribution of the invasive tunicate Didemnum vexillum. J Appl Ecol 46:64-72

Hollebone AL, Hay ME (2007) Propagule pressure of an invasive crab overwhelms native biotic resistance. Mar Ecol Prog Ser 342:191-196

Hulme P (2006) Beyond control: wider implications for the management of biological invasions. J Appl Ecol 43: 835-847

Hunt C, Yamada S (2003) Biotic resistance experienced by an invasive crustacean in a temperate estuary. Biol Invasions 5:33-43

Keane RM, Crawley MJ (2002) Exotic plant invasions and the enemy release hypothesis. Trends Ecol Evol 17:164-170

Lee SC, Bruno JF (2009) Propagule supply controls grazer community structure and primary production in a benthic marine ecosystem. Proc Natl Acad Sci USA 106:70527057

Levine JM (2000) Species diversity and biological invasions: relating local process to community pattern. Science 288:852-854

Levine JM, Adler PB, Yelenik SG (2004) A meta-analysis of biotic resistance to exotic plant invasions. Ecol Lett 7:975-989

Lockwood JL, Cassey P, Blackburn T (2005) The role of propagule pressure in explaining species invasions. Trends Ecol Evol 20:223-228

Maron JL, Vila M (2001) When do herbivores affect plant invasion? Evidence for the natural enemies and biotic resistance hypotheses. Oikos 95:361-373

Miller R, Etter R (2008) Shading facilitates sessile invertebrate dominance in the rocky subtidal Gulf of Maine. Ecology 89:452-462

Moreau S, Peron C, Pitt KA, Connolly RM, Lee SY, Meziane T (2008) Opportunistic predation by small fishes on epibiota of jetty pilings in urban waterways. J Fish Biol 72:205-217

Neill PE, Alcalde O, Faugeron S, Navarrete SA, Correa JA (2006) Invasion of Codium fragile ssp. tomentosoides in northern Chile: a new threat for Gracilaria farming. Aquaculture 259:202-210

Nydam M, Stachowicz JJ (2007) Predator effects on fouling community development. Mar Ecol Prog Ser 337:93-101

Osman RW, Whitlatch RB, Malatesta RJ (1992) Potential role of micropredators in determining recruitment into a marine community. Mar Ecol Prog Ser 83:35-43

Osman RW, Whitlatch RB (1995) Predation on early ontogenic life stage and its effect on recruitment into a marine epifaunal community Mar Ecol Prog Ser 117:111-126 
Osman RW, Whitlatch RB (2004) The control of the development of a marine benthic community by predation on recruits. J Exp Mar Biol Ecol 311:117-145

Parker JD, Hay ME (2005) Biotic resistance to plant invasions? Native herbivores prefer non-native plants. Ecol Lett 8:959-967

Ramsay A, Davidson J, Landry T, Arsenault G (2008) Process of invasiveness among exotic tunicates in Prince Edward Island, Canada. Biol Invasions 10:1311-1316

Rilov G (2009) Predator-prey interactions of marine invaders. In: Crooks J, Rilov G (eds) Biological invasions in marine ecosystems. Springer, Berlin, pp 261-286

Rius M, Branch GM, Griffiths CL, Turon X (2010) Larval settlement behaviour in six gregarious ascidians in relation to adult distribution. Mar Ecol Prog Ser 418:151-163

Ruiz G, Freestone A, Fofonoff P, Simkanin C (2009) Habitat distribution and heterogeneity in marine invasion dynamics: the importance of hard substrate and artificial structure. In: Wahl M (ed) Marine hard bottom communities. Springer, Berlin, pp 321-332

Simberloff D (2009) The role of propagule pressure in biological invasions. Annu Rev Ecol Evol Syst 40:81-102

Sousa WP (1984) The role of disturbance in natural communities. Annu Rev Ecol Syst 15:353-391

Stachowicz JJ, Whitlatch RB, Osman RW (1999) Species diversity and invasion resistance in a marine ecosystem. Science 286:1577-1579

Stachowicz JJ, Terwin JR, Whitlatch RB, Osman RW (2002) Linking climate change and biological invasions: ocean warming facilitates nonindigenous species invasions. Proc Natl Acad Sci USA 99:15497-15500

terHorst CP, Dudgeon SR (2009) Beyond the patch: disturbance affects species abundances in the surrounding community. J Exp Mar Biol Ecol 370:120-126

Thiel M, Macaya EC, Acuna E, Arntz WE, Bastias H, Brokordt K, Camus PA, Castilla JC, Castro LR, Cortes M, Dumont $\mathrm{CP}$, Escribano R, Fernandez M, Gajardo JA, Gaymer CF, Gomez I, Gonzalez AE, Gonzalez HE, Haye PA, Illanes JE, Iriarte JL, Lancellotti DA, Luna-Jorquerai G, Luxoroi C, Manriquez PH, Marin V, Munoz P, Navarrete SA, Perez E, Poulin E, Sellanes J, Sepulveda HH, Stotz W, Tala F, Thomas A, Vargas CA, Vasquez JA, Vega JMA (2007) The Humboldt Current System of northern and central Chile-oceanographic processes, ecological interactions and socioeconomic feedback. Oceanogr Mar Biol Annu Rev 45:195-344
Torchin ME, Lafferty KD, Dobson AP, McKenzie VJ, Kuris AM (2003) Introduced species and their missing parasites. Nature 421:628-630

Tyrrell M, Byers J (2007) Do artificial substrates favor nonindigenous fouling species over native species? J Exp Mar Biol Ecol 342:54-60

Underwood AJ (1997) Experiments in ecology: their logical design and interpretation using analysis of variance. Cambridge University Press, New York

Uribe E, Etchepare I (2002) Effects of biofouling by Ciona intestinalis on suspended culture of Argopecten purpuratus in Bahía Inglesa, Chile. Bull Aquac Assoc Can 102:93-95

Valdivia N, Heidemann A, Thiel M, Molis M, Wahl M (2005) Effects of disturbance on the diversity of hard-bottom macrobenthic communities on the coast of Chile. Mar Ecol Prog Ser 299:45-54

Vega JMA, Vasquez JA, Buschmann AH (2005) Population biology of the subtidal kelps Macrocystis integrifolia and Lessonia trabeculata (Laminariales, Phaeophyceae) in an upwelling ecosystem of Northern Chile: interannual variability and El Nino 1997-1998. Rev Chile Hist Nat 78:33-50

Verling E, Ruiz GM, Smith LD, Galil B, Miller AW, Murphy KR (2005) Supply-side invasion ecology: characterizing propagule pressure in coastal ecosystems. Proc R Soc Lond B Biol Sci 272:1249-1256

Viviani CA, DiSalvo LH (1980) Biofouling in a north-central Chilean coastal bay. In: Proceedings of the 5th international congress on marine corrosion foul. Barcelona, pp 69-74

von Brand E, Merino GE, Abarca A, Stotz W (2006) Scallop fishery and aquaculture in Chile. In: Shumway SE, Parsons GJ (eds) Scallops: biology, ecology and aquaculture. Elsevier, Amsterdam, pp 1293-1314

Von Holle B, Simberloff D (2005) Ecological resistance to biological invasion overwhelmed by propagule pressure. Ecology 86:3212-3218

Wanger TC, Wielgoss AC, Motzke I, Clough Y, Brook BW, Sodhi NS, Tscharntke T (2011) Endemic predators, invasive prey and native diversity. Proc R Soc B 278:690-694

Wasson K, Fenn K, Pearse J (2005) Habitat differences in marine invasions of Central California. Biol Invasions 7:935-948 